\title{
S wie Sally Rooney und VLSS
}

\section{Dominik Heim}

PD Dr. med., Facharzt für Chirurgie, Klinik Hohmad Thun/lexiatrik Luzern

Unterschiedlicher könnten sie nicht sein, die beiden Bücher, die ich gelesen habe: Erst die Grande Dame aus Bern von Karoline Arn Die Entourage von Elisabeth de Meuron-von Tscharner [1], und dann Beautiful world, where are you? [2] von Sally Rooney, das Buch über die Millennials.

Die beiden haben aber trotz der völlig unterschiedlichen Epoche etwas gemeinsam, sie berichten über eine Zeitperiode mit all ihren Eigenarten, ihren Zwängen und Freiheiten. Wobei man bei Elisabeth de Meuron eigentlich von Freiheiten nicht reden kann. Ihr Leben schockiert aus heutiger Sicht. Da waren gesellschaftliche Konventionen, die es einzuhalten galt. Heiraten konnte sie nicht den, den sie eigentlich wollte. Geheiratet hat sie dann Fritz de Meuron aus Erlach bei Neuenburg. Sie hatten zwei Kinder, einen Sohn, der sich mit 29 Jahren im Schloss erschoss, und eine Tochter, die in Tanger lebte, entfremdet von ihrer Mutter, und die später an Krebs starb, ohne dass vorher eine Verständigung zwischen Mutter und Tochter stattgefunden hatte. Das Buch erzählt vom Leben zwischen dem Elternhaus von Tscharner-von Wattenwyl in der Berner Altstadt und den beiden Schlössern Rümligen und Amsoldingen. Pächter bewirtschafteten das dazugehörige Land, und von diesen und anderen Persönlichkeiten berichtet dieses Buch. Eingeschoben sind Auszüge aus den zahlreichen Briefen

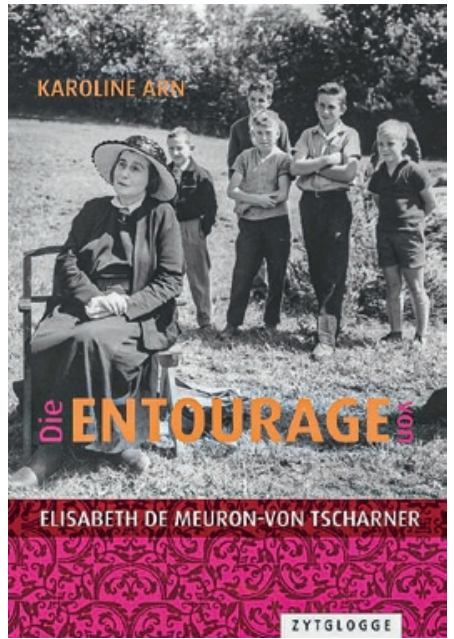

rund um sie herum beschreiben: Die Luft ist toxisch, im Wasser hat es Mikroplastik und im Essen hat es krebserregendes Teflon. Man ist sich einig, dass es mit der Zivilisation abwärtsgeht. Den Partner sucht man über Tinder, man ist ausgebrochen aus dem Elternhaus, das Leben scheint offen, man hat unkomplizierten Sex, aber so richtig froh wird man dabei nicht. Wo ist da eigentlich die schöne Welt? Und man realisiert (erstaunt?), dass das Leben trotz vielen, über die Jahrzehnte weggefallenen Konventionen nicht einfacher, nein, komplizierter geworden ist.

Denn das Leben betrifft ja nicht nur das (Zusammen-) Leben, es betrifft auch die eigene soziale Orientierung und die berufliche Ausrichtung. Als Babyboomer war für mich bald einmal klar, dass es Medizin werden sollte, wegen väterlichen Genen oder vorgelebter Berufswelt wurde es dann Chirurgie, und die Familie fand darin ihren Platz. Das ist heute anders.

Für die Millennials und die folgende Generation $\mathrm{Z}$ ist fast alles möglich, aber nicht einfacher. Nach einem Vortrag bei Medizinstudierenden «Werdegang nach dem Medizinstudium: Über den Alltag eines Arztes und über seine Studienjahre» wurde am Schluss angemerkt, das sei dann sehr anregend gewesen. Anregend ja, beratend ja, belehrend nein.

Darum sind Mentoring-Projekte oder das beratende Programm des Vereins von Madame de Meuron. Da war immer eine Hierarchie, und das Leben spielte sich im gesellschaftlich abgesteckten Rahmen ab. Eine freie Wahl war nur sehr beschränkt möglich. Die Rolle war vorgegeben.

Ganz anders die Geschichte, die Sally Rooney, die im Moment gefeierte dreissigjährige Bestsellerautorin aus Dublin, schildert. Ihre beiden Protagonistinnen, beide im ähnlichen Alter wie die Autorin, Alice, eine erfolgreiche Schriftstellerin, und Eileen, die in einem Verlagshaus arbeitet, kennen sich aus der gemeinsamen Schulzeit. Sie kommunizieren nicht (wie früher) mit Briefen, sondern senden sich längere E-Mails, in denen sie ihre Umgebung, ihre Gedanken, ihr Befinden und das Leben der leitenden Spitalärztinnen und -ärzte Schweiz (VLSS) "coach my career» für angehende Medizinerinnen und Mediziner so wichtig in einer Zeit, wo Althergebrachtes wie damals in den 68er Jahren (wo blieben eigentlich Woodstock und die Pflastersteine von Paris?) - nicht mehr gilt und ersetzt werden muss. Es war eine anregende Lektüre, die nachhallt!

"Coach my career» ist ein Partnerprojekt des VLSS mit FMH, VSAO, mfe und swimsa.

Literatur

1 Arn K. Die Entourage von Elisabeth de Meuron-von Tscharner. Basel: Zytglogge; 2021.

2 Rooney S. Beautiful world, where are you? London: Faber\&Faber; 2021 